N A T U R E

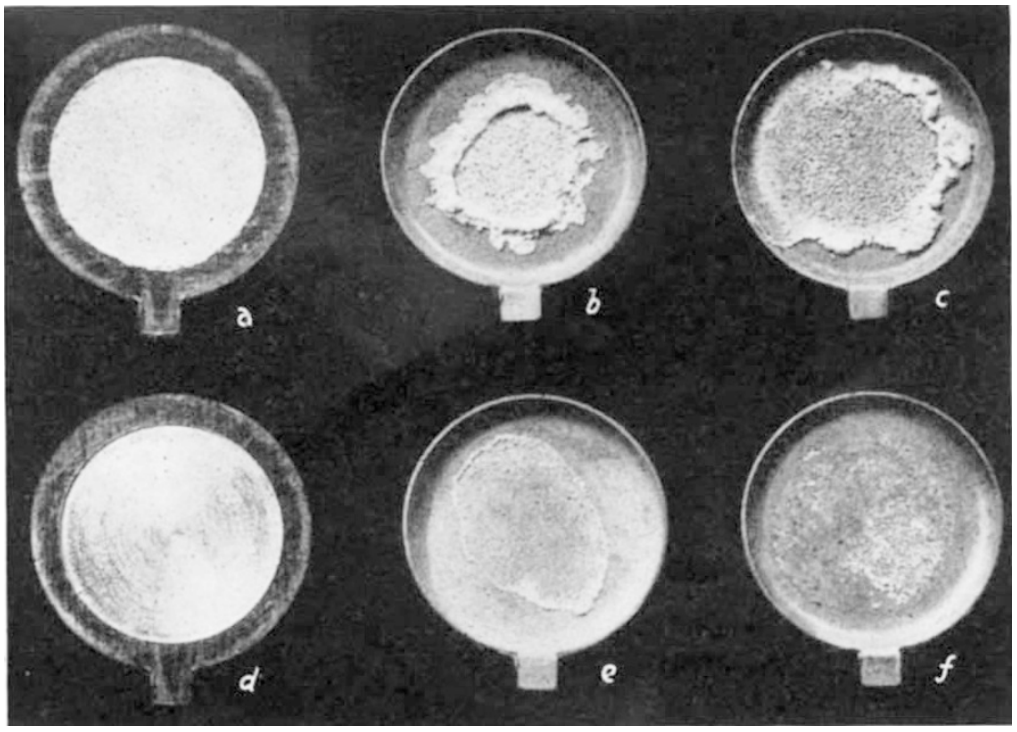

August 18, 1951 vol. 168

chamber to eliminate air scattering. The angle of scattering was $30+5^{\circ}$. The transmission of a lithium fluoride plate $(0 \cdot 14$ gm. $/ \mathrm{cm} .{ }^{2}$ ) was measured in positions 1 and 2 for different scattering samples. The transmission of the plate had been measured as a function of energy with a mechanical spectrometer, so that a mean energy of the beam could be determined from these measurements. From the measurement in position 1 the mean energy of the neutrons which are scattered into the counter is determined before they are scattered, and from the measurement in position 2 the mean energy is determined after scattering. The results are shown in the accompanying table.

The cross-section (assuming the scattering to be isotropic) was determined by calculating the ratio of scattering to total cross-section

distribution ; that is, there was no experimental evidence of difference between the disks.

In the course of some other work, a large number of sodium bromide deposits containing either sodium24 or bromine-82 have been tested using this method, taking three $0 \cdot 2-\mathrm{ml}$. samples from each solution (from solutions of varying concentration up to 1.0 molar), and each set of three samples also gave results within the Poisson distribution.

Figs. $a$ and $d$ indicate clearly, the uniform deposit obtained by this method, as compared with those obtained $(b, c)$ by evaporating the solution in a dish, or those $(e, f)$ when detergent is added to the solutions in the dish: In each case $0.2 \mathrm{ml}$. of sodium bromide has been used. Figs. $a, b$ and $c$ are for $1 \cdot 0 M$ and Figs. $d, e$ and $f$ for $0.1 M$ solutions.

My thanks are due to Dr. A. Robson for discussion.

Wool Industries Research Association, M. L. WRIGHT Torridon,

Headingley, Leeds 6. April 27.

${ }^{1}$ For example, Kohman, T. P., Anal. Chem., 21, 352 (1949).

\section{Inelastic Scattering of Cold Neutrons}

THE gain of energy of cold neutrons on being scattered by crystalline materials has been investig. ated with a beam of lead-filtered neutrons from the Harwell pile. The maximum energy of the neutrons in the beam was $0.0026 \mathrm{eV}$. and the mean energy was $0.0017 \mathrm{eV}$. The experimental arrangement is shown in the accompanying diagram. The counter and sample were carefully shielded from stray neutrons, and the sample was enclosed in a vacuum

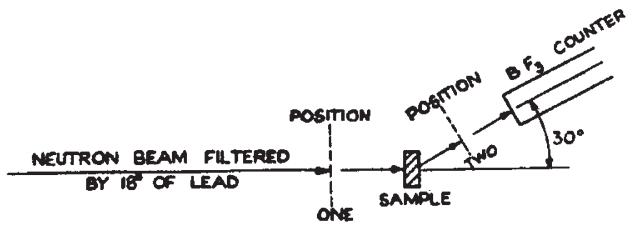
of the sample, from the ratio of the counting rates obtained with the sample and the thin hydrogenous sample.

\begin{tabular}{|c|c|c|c|c|c|}
\hline Element & $\begin{array}{l}\text { Thick- } \\
\text { ness in } \\
\text { mean } \\
\text { free } \\
\text { paths }\end{array}$ & $\underset{\text { energy* }}{1}$ & $\begin{array}{c}2 \\
\text { Final } \\
\text { energy }\end{array}$ & $\begin{array}{c}\text { Cross- } \\
\text { section } \\
\text { if } \\
\text { isotropic }\end{array}$ & $\begin{array}{l}\text { Cross- } \\
\text { section } \\
\text { determined } \\
\text { from trans- } \\
\text { mission } \\
\text { data }\end{array}$ \\
\hline $\begin{array}{l}\mathrm{H} \\
\mathrm{H} \\
\mathrm{H} \\
\mathrm{Be} \\
\mathbf{V} \\
\mathrm{Se} \\
\mathrm{Mo} \\
\mathrm{Fe}\end{array}$ & $\begin{array}{l}0 \cdot 81 \\
1 \cdot 4 \\
3 \cdot 4 \\
0 \cdot 60 \\
0.92 \\
1.06 \\
1.00 \\
0.98\end{array}$ & $\begin{array}{c}1 \cdot 75 \pm 0 \cdot 10 \\
1 \cdot 60 \pm 0 \cdot 10 \\
1 \cdot 75 \pm 0 \cdot 10 \\
1 \cdot 3 \pm 0 \cdot 3 \\
1 \cdot 7 \pm 0.2 \\
= \\
1 \cdot 65 \pm 0.25\end{array}$ & $\begin{array}{c}1 \cdot 75 \pm 0 \cdot 10 \\
2 \cdot 85 \pm 0 \cdot 25 \\
9 \cdot 3 \pm 1 \cdot 8 \\
5 \cdot 0 \pm 1 \cdot 7 \\
1 \cdot 5 \pm 0 \cdot 2 \\
\pm \\
9 \cdot 8 \pm 1 \cdot 8\end{array}$ & $\begin{array}{c}\bar{Z} \\
\bar{?} \\
6 \pm 1 \\
2 \cdot 5 \pm 1 \\
<0 \cdot 3 \\
1 \cdot 5 \pm 0 \cdot 5\end{array}$ & $\begin{array}{l}= \\
\bar{Z} \\
4 \cdot 7 \\
4 \pm 2 \\
<0 \cdot 3 \\
1 \cdot 4\end{array}$ \\
\hline
\end{tabular}

In the case of hydrogenous media, the presence of inelastic scattering is only observable with the thicker samples. In crystalline materials, the scattering cross-section at neutron wave-lengths greater than the Bragg limit is made up of inelastic scattering due to thermal vibrations and elastic incoherent scattering due to spin and isotope effects. The result with beryllium confirms that the inelastic cross-section is much greater than the incoherent cross-section, although the value for the final energy is too low because the inelastically scattered neutrons are appreciably Bragg-scattered. The vanadium measurements verify that the scattering is largely incoherent. The measurements with selenium and molybdenum were made to confirm the order of magnitude of the inelastic and incoherent cross-sections which had been determined from the total cross-section.

The scattering cross-section of iron $^{1}$ is known to be greater than the thermal inelastic cross-section at long wave-lengths, and the present measurements verify directly that the difference is due to inelastic scattering. It is believed that this is magneto-thermal scattering ${ }^{2}$.

P. A. Egelstaff

Atomic Energy Research Establishment,

Harwell, Nr. Didcot, Berks. April 16.

1 Hughes, Burgy and Woolf, Phys. Rev., 80, 481 (1950).

2 Moorhouse, Proc. Phys. Soc., 64, 207 (1951). 